\title{
Naturaleza jurídica del contrato de obra pública en relación con las cláusulas excepcionales como mecanismo para lograr el cumplimiento del objeto contractual ${ }^{1}$
}

\author{
Legal nature of the public works contract \\ in relation to the exceptional clauses as a \\ mechanism to achieve the fulfillment of the \\ contractual object
}

Jorge Luis Bastidas Crespo*

\section{Resumen}

Dentro de esas actividades de la contratación pública se encuentra el contrato de obra pública como uno de los instrumentos más completos para poder cumplir los fines del Estado. En la ejecución del contrato de obra pública se presenta una serie de acontecimientos que en ocasiones se desenvuelven en escenarios imprevistos y complejos, que accionan la utilización de las cláusulas excepcionales como herramientas legitimas del Estado para buscar satisfacer el interés general, proteger la moralidad pública, y así alcanzar el cumplimiento del objeto contractual.

1 Artículo de investigación.

* Abogado de la Universidad Popular del Cesar, especialista en Derecho Administrativo de la Universidad Militar Nueva Granada, magíster en Derecho Contractual Público y Privada de la Universidad Santo Tomas 
La presente investigación tiene por finalidad mencionar e identificar los diferentes conceptos y opiniones respecto al contrato de obra pública, la relación jurídica contractual que se desenvuelve entre el Estado y el contratista, cuando el primero haga uso de las facultades excepcionales que otorga la ley para evitar la paralización o la afectación grave de los servicios públicos y poder suplir la inmediata, continua y adecuada prestación del servicio. Por lo que se realiza una aproximación al concepto de cláusulas excepcionales, asimismo, tratar su marco legal y su desarrollo, para analizar si cumplen con su finalidad cuando son aplicadas de manera practica en el desarrollo y ejecución del contrato de obra pública.

\section{Palabras claves}

Contrato de obra, Cláusulas excepcionales, Interés general, Prerrogativas, Legitimidad.

\section{Abstract}

Among these public procurement activities, the public works contract is one of the most complete instruments to be able to fulfill the purposes of the State, said public works contract in its execution, a series of events are presented that sometimes unfold in unforeseen and complex scenarios that trigger the use of exceptional clauses as legitimate tools of the State to be able to seek to satisfy the general interest, protect public morality, to achieve compliance with the contractual object.

The purpose of this research is to mention and identify the different concepts and opinions regarding the public works contract, the contractual legal relationship that develops between the State and the contractor, this in development that the former makes use of the exceptional powers granted by the Law, to avoid the paralysis or serious impairment of public services and to be able to supply 
the immediate, continuous and adequate provision of the service. Therefore, an approach is made to the concept of exceptional clauses, treating their legal framework and the development thereof by virtue of whether they fulfill their purpose, when they are applied in a practical way in the development and execution of the public works contract.

\section{Key words}

Work contract, Exceptional clauses, General interest, Prerogatives, Legitimacy.

\section{Introducción}

Siendo el contrato de obra pública una de las herramientas más visibles y pragmáticas del Estado para llevar al ciudadano de bienes y servicios, se denota en ocasiones que el contrato de obra pública no llega a ejecutarse en su totalidad, ya que la administración hace uso legítimo de las cláusulas excepcionales, que es una facultad exclusiva otorgada por la Ley para evitar la paralización o la afectación grave de los servicios públicos a su cargo y asegurar la inmediata, continua y adecuada prestación, en síntesis, su posible cumplimiento contractual.

Asimismo, dentro de las actividades de la administración pública está la de velar y satisfacer a la ciudadanía, haciendo uso de instrumentos jurídicos de la administración pública. Entre esos instrumentos encontramos la contratación estatal. En el tema que pretendemos analizar articuladamente se encuentra el contrato de obra pública, el cual trae una serie de actuaciones procesales y sustanciales para su posible cumplimiento.

Dentro de la contratación pública encontramos al contrato de obra pública como uno de los instrumentos más complejos para po- 
der cumplir el objeto contractual, ya que dicho contrato de obra, desde sus diferentes etapas precontractual, contractuales y poscontractual, termina abriendo una fisura entre el contratante y contratista, acarreando secuelas como retrasos, parálisis, suspensiones indeterminadas, modificaciones unilaterales, adiciones improvisadas, interpretaciones unilaterales, proceso sancionatorio, entre otras figuras que afectan de manera grave y notoria la ejecución contractual de un contrato de obra, a lo que el contratante hace uso de las cláusulas excepcionales con la intención de evitar parálisis o afectación de servicios públicos y asegurar el cumplimiento del objeto contractual, y, asimismo, poder cumplir a satisfacción el interés general.

De lo anterior hay casos en los que la administración, en el contrato de obra pública, hace uso de las cláusulas excepcionales con el fin de evitar la parálisis o afectación de servicios públicos; sin embargo, en ocasiones se percibe que el uso de esas herramientas legitimas arrastran la ejecución de los contratos de obras en desgastantes, como lo son trámites administrativos, disciplinarios, judiciales y fiscales. Entonces, el fin de esta investigación es demostrar o declarar la correcta y eficiente utilización de estos mecanismos; pero mientras eso sucede, surge el siguiente interrogante: ¿la utilización de las cláusulas excepcionales son o no la herramienta adecuada para asegurar el cumplimiento del objeto contractual en el contrato de obra pública en Colombia? Para responder lo anterior se fijará una hipótesis afirmativa, según lo emanado por la normatividad colombiana al contrato de obra pública en relación con las cláusulas excepcionales, estas miradas como facultades superiores que brinda la Ley, para materializar y dar prioridad al interés general, ante un acontecimiento adverso que afecte o retrase la inmediata, continua y adecuada prestación de un servicio en el contrato de obra pública.

Para brindar una posible respuesta, al interrogante de esta investigación es pertinente plantearse como objetivo general la delimitación del concepto del contrato de obra pública en la normatividad 
colombiana y la utilización de las cláusulas excepcionales de acuerdo con lo establecido en el artículo 14 de Ley 80 de 1993. De la misma manera, es pertinente como objetivo específico l) analizaran y articular lo estipulado y reglado por la ley respecto al concepto de las cláusulas excepcionales; por otro lado, se adoptará como objetivo específico 2) analizar las opiniones de la doctrina en cuanto la definición de cláusulas excepcionales, su fundamento axiológico y la utilización de esta como herramientas legítimas para evitar la parálisis o afectación grave de la prestación del servicio, y, por último, se implementará como objetivo específico 3) proponer la articulación de medios más expeditos en el contrato de obra que permitan el cumplimiento del contrato estatal, sin hacer uso excesivo de las cláusulas excepcionales.

Por otro lado, se invitará a implementar o articular esfuerzos institucionales y particulares que permitan desarrollar estrategias preventivas y operativas que permitan el abordaje sistemático de una manera específica al avance significativo, real y material dentro del desarrollo contractual del contrato de obra pública, consolidando y respetando el cumplimiento del objeto contractual, en virtud del interés general.

Este trabajo es de vital importancia desarrollarlo, analizarlo, llevarlo a cabo y darlo a conocer, ya que se vislumbra, en ocasiones, que el uso de las cláusulas excepcionales en la ejecución del contrato de obra evita la paralización o afectación grave de los servicios públicos a cargo del Estado; por lo que, en la esfera material y operativa, la utilización dentro de la actuación administrativa de las cláusulas excepcionales (interpretación, modificación, terminación unilateral, caducidad y revisión) del contratante, no se evidencia el cumplimiento del objeto contractual señalado en el artículo 14 de la Ley 80 de 1993.

La presente investigación (de carácter cualitativo y de enfoque hermenéutico crítico y propositivo) se llevará a cabo a través de una 
revisión documental, en donde prima el análisis doctrinal y legislativo. Además, se analizará la implementación normativa de las cláusulas excepcionales asociadas de manera obligatoria en el contrato de obra pública.

Se mencionará brevemente el origen y antecedentes del contrato de obra pública, algunas opiniones respecto a esta tipología contractual, se mencionarán algunas características de acuerdo con su tipificación en el marco normativo. Luego, se tratará el concepto de las cláusulas excepcionales, su fundamento legal y características; posteriormente, se analizará lo establecido en la ley y las opiniones de la doctrina.

Consecuentemente con lo anterior, se pretenderá a articular, relacionar y concluir si la utilización de las cláusulas excepcionales en el contrato de obra pública es la herramienta más idónea y pragmática para el cumplimiento del objeto contractual; por lo que, a continuación, desarrollaremos el concepto y opiniones del contrato de obra pública en el siguiente capítulo.

\section{Capítulo I. El contrato de obra pública}

El origen histórico del contrato de obra pública ha estado en la evolución y desarrollo constante de la humanidad, convirtiéndose en una figura jurídica del Estado, que le permitían desarrollar de forma inicial y básica conocimientos en contabilidad, aplicables a la administración pública y en hacienda privada (Camacho, 2008).

La figura del contrato de obra inicialmente entre particulares fue aceptada y comúnmente utilizada de tal manera que se estableció como puente para poder lograr estrategias de acercamiento entre la sociedad y el Estado, ya que el desarrollo y la reglamentación de la figura del contrato se legitimaron para buscar procesos de crecimiento político jurídico y económico. 
Posteriormente, surgió la necesidad entre gobernante y los súbditos de buscar mejores condiciones de vida dentro de las sociedades humanas, como lo menciona Vargas (2010):

Estas obras adquieren el carácter de publicas cuando son realizadas con recursos aportados por el Estado y cuyo objetivo es principalmente de carácter social, es decir que benefician, en principio a una parte o la totalidad de la población gobernada (p. 20).

Por lo anterior, es importancia entender el concepto de contrato de obra, pero no hay un concepto unánime y universal en la materia de investigación, ya que varía de acuerdo con la historia, desarrollo y legislación de cada país (Pino, 2005). No obstante, la doctrina ha venido desarrollando un concepto casi conexo acerca del contrato de obra. Sin embargo, conseguimos conceptos unos más amplios que otros como el de Vargas (2010), donde dice que los contratos de obras públicas son:

Aquellas realizaciones físicas que debe ejecutar el Estado para proporcionar el crecimiento integral de las estructuras sociales y económicas de la nación, manteniendo el medio ambiente con la menor intervención negativa posible y por ende los menores impactos, dotando su estructura institucional de todas las condiciones administrativas, técnicas, jurídicas, legales, financieras y logísticas adecuadas para ser eficientes y eficaces en ese cometido gubernamental (Vargas, 2010, p. 19).

Del concepto anterior, se encuentra un concepto completo y práctico de acuerdo con lo que se encuentra en el medio de la figura del contrato de obra dentro de contratación estatal, vista esta como herramienta para conseguir los fines esenciales del Estado.

No obstante, vemos otros doctrinantes que tienen un concepto más sencillo del contrato de obra pública, como es el caso de Máximo Bezzi (1982): "Obras públicas son aquellas realizadas por el 
Estado directamente o por contratistas, siendo indiferente su afectación al uso público o incorporación al dominio privado del Estado" (p. 11). Del concepto anteriormente mencionado se vislumbra un modo sencillo para definir el contrato de obra pública.

Adicional existen conceptos aún más sencillos en su expresión, pero contundentes, como lo manifiesta Parra (1999): "Los contratos de obras públicas son aquellos mediante los cuales la administración conviene con un empresario privado la construcción o el mantenimiento de un inmueble de interés público” (p. 4). Se evidencia que este concepto va más acorde a la satisfacción del interés general.

Del mismo modo seguimos mencionando y analizando más conceptos, como el de Rodríguez (2015), quien manifiesta que los contratos de obras públicas son "los instrumentos más utilizados por el Estado para satisfacer la carencia pública” (p. 520); entonces, es un mecanismo muy utilizado por el Estado Social de Derecho para realizar y materializar actuaciones frente a los ciudadanos y satisfacer sus necesidades.

Siendo la definición anterior más que una definición del concepto del contrato de obra pública, se puede observar que es un medio material y legitimo para lograr resultados de una política de Estado, o como lo dice Fandiño (2014), es el medio "por construir la representación material de los propósitos de los gobernantes y de las organizaciones que dirigen” (p. 316).

Ahora bien, acercándose a la definición normativa del contrato de obra que menciona el numeral 1 del artículo 32 de la Ley 80 de 19932,

2 "Son contratos de obra los que celebren las entidades estatales para la construcción, mantenimiento, instalación y, en general, para la realización de cualquier otro trabajo material sobre bienes inmuebles, cualquiera que sea la modalidad de ejecución y pago..." (Ley 80, 1993, art. 32). 
se puede evidenciar la definición del contrato de obra (que regula esta misma Ley) trae varias particularidades, entre ellas que los que celebran los contratos deben ser entidades públicas ${ }^{3}$, a la vez que las actividades de construcción, mantenimiento, instalación, entre otras actividades que amerite la actividad contractual, deben de recaer en bienes inmuebles. A estas actividades, según Parra (1999), la doctrina las alcanzó a clasificar en tres modalidades ${ }^{4}$.

Lo anterior puede ser interpretado en un tipo de silogismo contractual, ya que el contrato de obra pública tiene que estar visualizado, materializados y ejecutado en inmuebles de carácter público o directamente destinados a un servicio público, sin embargo, existe una posición distante del profesor Marienhoff (1980) que vale la pena conocer ${ }^{5}$, posición compartida por los tratadistas Bielsa y Fiorini en su obra ${ }^{6}$.

Por lo anterior, se puede establecer que el contrato de obra en ocasiones no es solamente considerado como un negocio jurídico

3 Las entidades públicas con las definidas en el artículo 2 de la ley 80/93 10. Se denominan entidades estatales: "a) La Nación, las regiones, los departamentos, las provincias, el distrito capital y los distritos especiales, las áreas metropolitanas, las asociaciones de municipios, los territorios indígenas y los municipios; los establecimientos públicos, las empresas industriales y comerciales del Estado, las sociedades de economía mixta en las que el Estado tenga participación superior al cincuenta por ciento (50\%), así como las entidades descentralizadas indirectas y las demás personas jurídicas en las que exista dicha participación pública mayoritaria, cualquiera sea la denominación que ellas adopten, en todos los órdenes y niveles". (Ley 80, 1993, art. 2)

4 "Construcción de la obra por parte del Estado en forma directa; Construcción de la obra por medio de un contrato de obras públicas, y Construcción de la obra por un particular en desarrollo de un contrato de concesión." (Parra, 1999, p. 109).

5 "Obra pública no solo puede referirse a un inmueble, sino también a muebles y a objetos inmateriales, tanto más cuando hay obras públicas por accesoriedad" (Marienhoff,1980, p,502).

6 " "...) por su parte Bielsa afirma que la distinción que hace en cuento a que la obra pública debe ser referida los inmuebles solamente y que cuando se trata de muebles la operación se llama suministro, es convencional y arbitraria, porque la obra pública puede ser tan importante 0 más aun sobre muebles que sobre inmuebles, y también es ciertos casos el grado de utilidad 0 de interés público ser mayor en los primeros que en los segundos. Por su parte Fiorini sostuvo que: la unidad jurídica "obra pública" puede referirse a cosas que la ciencia del derecho denomina muebles 0 inmuebles... Los muebles para un edificio público pueden entrar en esta calificación, si se ajustan a un bien público." (Máximo, 1982, p. 13) 
generador de obligaciones, sino como mecanismo para realizar actuaciones de construcción o trabajos que se ejecuten con personal técnico y fondos públicos de la administración pública.

No obstante, la aserción más completa, sólida y acertada, después de haber mencionado y analizado las diferentes opiniones, nos exhorta a buscar, compartir y fijar una posición respecto al contrato de obra; por lo que después de estudiar las diferentes opiniones podemos compartir el concepto del contrato de obra del maestro García de Enterría y Fernández como uno de los concepto más importante y respetado, el cual manifiesta:

Es aquel que tiene por objeto la construcción, reforma, reparación, conservación o demolición de un bien inmueble o la realización de trabajos que modifiquen la forma o sustancia del suelo o del subsuelo por cuenta de la Administración a cambio de un precio. Esta definición fue sustituida (...) por otra más abstracta y mucho menos expresiva que entiende por obra el resultado de un conjunto de trabajos de construcción o de ingeniería civil, destinado a cumplir por sí mismo una función económica o técnica que tenga por objeto un bien inmueble, sustitución que no tiene mayor trascendencia (García de Enterría y Fernández, 2014, p. 776-777).

De acuerdo con la anteriores definición del contrato de obra pública se observa, cómo se mencionó al principio de este capítulo, que no hay unanimidad ni una corriente absoluta a dicho concepto; no obstante, ambos conceptos dejan una base sólida respecto al contrato de obra, con características innegables, como lo son realizar un trabajo de construcciones o mantenimiento sobre bienes inmuebles; este trabajo debe ser remunerado y una de las partes siempre será una entidad pública delegada por la ley para conseguir el interés general con la materialización de dicho contrato de obra pública.

Siendo la figura del contrato de obra pública una de las herramienta más utilizada y certera por la administración, para demostrar 
su acercamiento y a la vez para satisfacer las necesidades representativas dentro de las políticas de Estado, es importante mencionar las características propias de esta figura contractual, por lo que debemos precisar que el contrato de obra tiene unas particularidades que son propias de su tipología contractual, como que son nominados o típicos, bilaterales, onerosos, conmutativos, formales o solemnes, intuitu personae y de tracto sucesivo.

\section{Ahora bien, ya habiendo dado a conocer diferentes opiniones del contrato de obra pública, es pertinente asegurar que este tipo de contrato permite, por mandato legal ${ }^{7}$ dentro de la Ley 80 de 1993,}

$7 \quad$ Art. 14. "De los medios que pueden utilizar las entidades estatales para el cumplimiento del objeto contractual. Para el cumplimiento de los fines de la contratación, las entidades estatales al celebrar un contrato:

1. Tendrán la dirección general y la responsabilidad de ejercer el control y vigilancia de la ejecución del contrato. En consecuencia, con el exclusivo objeto de evitar la paralización o la afectación grave de los servicios públicos a su cargo y asegurar la inmediata, continua y adecuada prestación, podrán, en los casos previstos en el numeral segundo de este artículo, interpretar los documentos contractuales y las estipulaciones en ellos convenidas, introducir modificaciones a lo contratado y, cuando las condiciones particulares de la prestación así lo exijan, terminar unilateralmente el contrato celebrado. En los actos en que se ejerciten algunas de estas potestades excepcionales deberá procederse al reconocimiento y orden de pago de las compensaciones e indemnizaciones a que tengan derecho las personas objeto de tales medidas y se aplicarán los mecanismos de ajuste de las condiciones y términos contractuales a que haya lugar, todo ello con el fin de mantener la ecuación o equilibrio inicial. (...)

2. Pactarán las cláusulas excepcionales al derecho común de terminación, interpretación y modificación unilaterales, de sometimiento a las leyes nacionales y de caducidad en los contratos que tengan por objeto el ejercicio de una actividad que constituya monopolio estatal, la prestación de servicios públicos o la explotación y concesión de bienes del Estado, así como en los contratos de obra. En los contratos de explotación y concesión de bienes del Estado se incluirá la cláusula de reversión. Las entidades estatales podrán pactar estas cláusulas en los contratos de suministro y de prestación de servicios. En los casos previstos en este numeral, las cláusulas excepcionales se entienden pactadas aun cuando no se consignen expresamente.

PARÁGRAFO. En los contratos que se celebren con personas públicas internacionales, o de cooperación, ayuda o asistencia; en los interadministrativos; en los de empréstito, donación y arrendamiento y en los contratos que tengan por objeto actividades comerciales o industriales de las entidades estatales que no correspondan a las señaladas en el numeral 2. de este artículo, o que tengan por objeto el desarrollo directo de actividades científicas o tecnológicas, así como en los contratos de seguro tomados por las entidades estatales, se prescindirá de la utilización de las cláusulas o estipulaciones excepcionales” (Ley 80, 1993, art.14). 
el uso de las llamadas cláusulas excepcionales, condición esta que si bien es denominada como cláusula en esta tipología no se aprecia como un acuerdo o disposición consensuada entre los extremos contractuales; ya que es una imposición legal aceptada, por dichas partes en aras de salvaguardar el cumplimiento del objeto contractual, por lo que es necesaria abordar conceptos y opiniones de las cláusulas excepcionales y mencionar sus características.

Por lo anterior, iniciaremos manifestando que las cláusulas excepcionales son unas facultades discrecionales extraordinarias y superiores que otorga la ley a las entidades públicas para dotarlas de herramientas, con la finalidad de asegurar el cumplimiento del interés general (Escobar, 1999). Inicialmente, se observa una desigualdad jurídica entre el contratista y el contratante al momento de la ejecución del contrato de obra, ya que dichas clausulas deberán ser incorporadas y posiblemente utilizadas por la entidad estatal, sin discusión alguna de su legitimidad y sin concepto previo de aprobación de la contraparte ni negociación alguna (Dávila, 2016).

Dicho de otra manera, la administración puede hacer uso de las cláusulas excepcionales de manera unilateral cuando pretenda y tenga como finalidad salvaguardar el cumplimiento del contrato, justificando proteger el interés general, materializado con la entrega o ejecución del contrato de obra según sea el caso, por ello, el papel fundamental que juegan las cláusulas excepcionales dentro de los contratos de obra. Por esto se tolera y accede a su modificaciones sin observancia de lo pactado (pacta sunt servanda, o lex inter partes), compartiendo de esta manera lo manifestado por Palacio (2011), quien indica que:

Las cláusulas excepcionales están originadas en la necesidad de dar satisfacción al prioritario interés general o colectivo, que no es otro que posibilitar que el Estado lleve a feliz término sus proyectos, mediante el uso de medidas extremas que van desde la finalización anticipada del acuerdo, 
aparejada de sanciones específicas, hasta la aplicación del principio de la "mutabilidad de las relaciones contractuales" quebrantándose con ellos, principios clásicos del derecho privado, como el de "pacta sunt servanda" y el de igualdad contractual (Palacio, 2011, p. 75).

No obstante, la utilización de las cláusulas excepcionales, si bien es vinculante por mandato de la ley, se debe precisión que también tiene límites ante la propia ley, ya que esta encuentra su aplicabilidad de manera taxativa, es decir, se mueve en unos extremos que solo le permite el artículo 14 de la Ley 80 de 1993; por otro lado, es importante mencionar que la utilización de dichas cláusulas lleva en algunos casos un tipo de resarcimiento económico.

Sobre lo anterior señala Parada (1992), los extraordinarios poderes que la Administración ostenta en el contrato sobre el fondo y la forma, y que proyectan sobre la relación contractual una profunda desigualdad entre las partes, tienen una importante contrapartida en el derecho del contratista al equilibrio económico y que se concretan en el resarcimiento o indemnización de daños y perjuicios:

En conciencia, se observa que en diversos conceptos que la utilización de las cláusulas excepcionales, no nacen de un acuerdo de voluntades de las partes, sino que es una prerrogativa, facultad y/o poder de superioridad que otorga la Ley al Estado en sus relaciones negóciales (p. 275).

De todo lo anterior, se puede inferir que el concepto del contrato de obra es amplio, discutido, siempre debatido por la doctrina como figura de transferencia y materialización de los fines del Estado; sin embargo, dicho contrato, por la gran representación que tiene en las relaciones negóciales de la administración, va impregnado de acontecimientos contractuales especiales, que lo obligan a ser objeto de estudio, consulta y debate constante, como es el caso de la utilización de cláusulas excepcionales, inherentes a esta tipología contractual. Así, es necesario que desarrollemos a continuación los 
conceptos, características fundamento legal y opiniones de diferentes tratadistas en referencia a las cláusulas excepcionales.

\section{Capitulo II. Naturaleza jurídica de las potestades excepcionales como facultades de la administración pública}

Una vez abordadas diferentes opiniones respecto al contrato de obra pública, se hace necesario tratar y profundizar el conceptos y opiniones de las cláusulas excepcionales, entendidas estas como la interpretación unilateral, modificación unilateral, liquidación unilateral, caducidad y revisión de contratos, la cuales tienen una característica muy particular entre el extremo contractual que representa al Estado: por su poder de sometimiento al contratista y su amplia ventaja legal del contratante en virtud de conseguir el interés general; por lo que es prioridad abordar en principio de donde se fundamentan la utilización de dichas cláusulas.

Concomitante con lo anterior, es pertinente manifestar que esta supremacía legal y jurisdiccional tiene su razón de ser en dotar de herramientas, también llamadas "potestades o prerrogativas", al Estado para que realice una posible representación, ejerciendo su institucionalización, dando su prevalencia en trazar y conseguir la materialización del interés colectivo por encima del interés particular (Bondenhemir,1997), permitiéndoles a estas prerrogativas avasallar el concepto de un previo acuerdo de voluntades, ya que esta originalidad propia de los contratos estales, según Vendel (1980):

Provienen del hecho de que los contratos administrativos contienen cláusulas exorbitantes en su propio texto. En este caso las prerrogativas de la administración no son más que la aplicación del propio contrato. Por el contrario, algunas no tienen origen contractual y si se pactan, existirían, aunque no lo estuvieran porque son la consecuencia del régimen de potestad pública al que se hallan sometidas (p. 205). 
Abonado a lo anterior, frente a las potestades o prerrogativas se debe tener en cuenta que no surgen propiamente del acuerdo de voluntades que se materializan al elevarse por escrito el contrato estatal, sino que estas derivan de la importancia que tiene la administración al proyectar y ejecutar un contrato estatal, visto este como un instrumento para cumplir los fines estatales, así como lo expresa Rodríguez (2015):

El principio general de las prerrogativas o privilegios de la entidad pública, que se originan o se fundamentan en las potestades públicas que goza, y que le dan poderes de mando, de control y sanción. Se ha advertido que mientras el derecho privado considera la relación entre los particulares en un plano horizontal de igualdad jurídica, en cambio en derecho administrativo en general el público, considera la relación estado-administrados en un plano vertical, en virtud del poder de imperio y por lo tanto de las prerrogativas de que disfruta la entidad pública, que son exorbitante del derecho común. Por motivo de tales privilegios, el administrado está colocado en dicha relación en un estado de desigualdad jurídica.

Entendiendo lo anterior como esa hegemonía legal que tiene el contrato estatal en virtud de sus prerrogativas para ponderar derechos individuales versus derechos colectivos y poder proteger el cumplimiento del objeto contractual, así lo modificado, alterado o destruido, no haya sido objeto de acuerdo entre las partes, ya que, si bien en un contrato de carácter privado, los particulares buscan en su mayoría un beneficio económico, en el contrato de carácter estatal el Estado busca satisfacer una necesidad pública (Cassese, 1994).

Inicialmente se podría llegar a pensar que el uso de prerrogativas o facultades de la administración sería un pleno abuso del derecho de una de las partes, en referencia a su aplicabilidad en el desarrollo de un contrato debidamente pactado entre un particular y el Estado; sin 
embargo, esta prerrogativa o facultad debe entenderse siempre como un poder para ajustar las condiciones contractuales en víspera de arreglar, corregir, modificar y alterar lo inicialmente consensuado. Al respecto menciona García:

(...) esa clase de comportamientos irregulares, lo suministra el ejercicio del llamado "poder de negociación" por parte de quien, encontrándose de hecho o por derecho en una posición dominante en el tráfico de capitales, bienes y servicios, no solamente ha señalado desde el principio las condiciones, en que se celebra determinado contrato, sino que en la fase de ejecución o cumplimiento de este último le compete el control de dichas condiciones configurándose en este ámbito un supuesto claro de abuso cuando, atendidas las circunstancias particulares que atienden el caso, una posición de dominio de tal manera resulta siendo aprovechada, por acción o por omisión, con detrimento del equilibrio económico de la contratación (2017, pp. 178-179).

Por lo que, si bien la posición del participar en el desarrollo del contrato va a ser de inferioridad respecto a su contraparte (el Estado), esto siempre será un riesgo que tendrá que asumir el contratista en aras de ser ese colaborador y partícipe con de la administración, para que esta consiga unos fines públicos; dicho de otra manera, las prerrogativas son herramientas que permiten mutabilidad al contrato estatal para garantizar la adecuada y correcta prestación de los servicios públicos (Matallana, 2015).

Ahora bien, para que una de las partes tenga estas prerrogativas o facultades que le permitan hacer uso de las cláusulas excepcionales, es necesario que un extremo contractual tenga representación del Estado, para que se configure el contrato estatal, o lo que algunos tratadistas denominan contrato administrativo, visto este en principio aún como un acuerdo de voluntades que tiene efecto legal, es decir, su pacto, convención es ley para las partes, con la misma fuerza de obligatoriedad como en los contratos privados (Escola, 1979). 
Sin embargo, al tener en cuenta que una de las partes mantiene la representación del Estado, esta puede modificar lo estipulado en el contrato por medio de herramientas, como lo son las cláusulas excepcionales, ya que el propio Estado no puede prescindir de su carácter de poder, aun en las relaciones comerciales (Marienhoff, 1983), con la excusa de respetar el consentimiento de un particular que busca satisfacer sus propias necesidades y no satisfacer una necesidad pública por parte del Estado.

Por lo que los contratos estatales implican decisiones de la administración o de la ley que les permiten ser unilaterales, tendientes a cambiar cualquier condición, no dejándolo atado al cumplimiento total de lo pactado inicialmente en el contrato, sino que, por el contrario, permite maniobrar circunstancias previsibles e imprevisibles en probidad de conseguir o mantener el interés general y un buen servicio público (Güecha, 2015).

Por ello, para hacer uso de estas prerrogativas o facultades administrativas que ostenta la administración pública, debe tenerse en cuenta que el plano de horizontalidad jurídica pasa desapercibido de acuerdo con la exorbitancia del derecho común que poseen las cláusulas excepciones dentro de los contratos estatales, también llamados contratos administrativos. Estas tipologías contractuales se encuentran dentro del dinamismo del derecho administrativo, por lo que vale la pena mencionar brevemente una acotación en referencia a lo anterior:

En el ámbito del Derecho Administrativo se aminora la rigidez del pacta sunt servanda. La satisfacción del interés general tiene primacía sobre la incondicionada fidelidad a lo pactado, y explica que las normas introduzcan distintas dosis de ductilidad o elasticidad en el puro respeto y estricto cumplimiento de los acuerdos alcanzados. Por tanto, se trata de analizar la tensión dialéctica entre la justicia y la seguridad jurídica del pacta sunt servanda; debe ponderarse la 
justicia colectiva representada por la satisfacción del interés general, pero también la justicia conmutativa para los intereses individuales de las partes del contrato. (Blanquer, 2010, p. 115)

Lo anterior se menciona ya que la utilización de las cláusulas excepcionales en el ámbito contractual del contrato estatal fragmenta abruptamente ese paradigma rígido del derecho contractual privado, que todo contrato celebrado es ley para las partes y que debe cumplirse a cabalidad de lo pactado; no obstante, se observa de lo anteriormente citado que el soporte legal para poder modificar de manera unilateral lo pactado es abanderar el cumplimiento del contrato estatal, intentando satisfacer el interés general por medio de herramientas y actividades relacionadas con la administración pública (Montaña, 2010).

Visto de otra manera, no sería lógico y justo que el Estado quedara atado de manos en sus actuaciones administrativas bajo la figura de un contrato si por encima de esta figura jurídica está en riesgo la satisfacción del interés general, ya que el Estado puede hacer uso de las prerrogativas o facultades que tienen inmersas las cláusulas excepcionales, sin que existan limites por parte del particular bajo el reparo de un contrato. Al respecto han manifestado García de Enterría y Fernández (2006) lo siguiente:

Límites en este sentido no existen ni pueden existir, porque las exigencias del interés público, el servicio a la comunidad, no pueden quedar comprometidos por el error inicial de la Administración contratante o por un cambio en la circunstancia originariamente tenidas en cuenta en el momento de contratar. El interés general debe prevalecer en todo caso y en cualquiera de las circunstancias, porque, de otro modo, sería la propia comunidad la que habría de padecer las consecuencias. Obligar a la comunidad a soportar una carretera, un puerto, o un embalse mal planteado ab initio, inútiles o ineficaces desde su misma concepción, por un simple respeto del contractus lex, no tendría sentido. Al servicio del interés 
público y de sus concretas e insoslayables exigencias, el ius variandi de la Administración contratante es ilimitado en extensión e intensidad, ya que el interés público prima sobre cualquier otra consideración (p. 794).

Consecuentemente, se puede manifestar que el concepto de cláusulas excepcionales tiene su fundamento en las prerrogativas o facultades que brinda el legislador, que se materializan dentro de la normatividad colombiana por medio del artículo 14 de la Ley 80 de 1993, moldeadas estas como los medios que pueden utilizar las entidades estatales para el cumplimiento del objeto contractual.

Ahora bien, habiendo mencionado que dichas cláusulas poseen facultades o prerrogativas como una de sus características más peculiares y representativas, también es pertinente mencionar otra serie de características que le ayudan a su identificación e inclusión de manera más clara al momento de su uso.

Dentro de estos distintivos encontramos que las cláusulas excepcionales se encuentran en el ordenamiento jurídico contractual de manera taxativa, es decir, no permite duda, ambigüedad e interpretación alguna al operador jurídico contractual, ya que están señaladas de manera clara y directa en la citado artículo 14 de la Ley 80 de $1993^{8}$.

Por otro lado, se observa su aplicación e inaplicación de manera enunciativa en los tipos de contrato que autoriza el numeral 2 del artículo 14 de la Ley 80 de 1993, teniendo a la vez estos tipos de contratos una especie de división debido a su inclusión, aplicación e inaplicabilidad, ya que en algunos su aplicación es obligatoria y otras facultativas; de igual manera, el mismo marco legal señala en cuales contratos es prohibida la utilización de estas cláusulas, como se menciona en la siguiente Tabla 1 :

8 Ver pie de página $\mathrm{n}^{\circ} 6$ de este documento. 
Tabla 1.

Cláusulas excepcionales de acuerdo con la tipología contractual

\begin{tabular}{|l|l|l||}
\hline \multicolumn{3}{|c|}{ Cláusulas Excepcionales (Ley 80 de 1993) vs. Tipología Contractual } \\
\hline Inclusión obligatoria & Inclusión prohibitiva & Inclusión facultativa \\
\hline $\begin{array}{l}\text { Contratos que tengan por } \\
\text { objeto el ejercicio de una } \\
\text { actividad que constituya } \\
\text { monopolio estatal. }\end{array}$ & Contratos interadministrativos. & $\begin{array}{l}\text { Contratos de prestación de } \\
\text { servicios. }\end{array}$ \\
\hline $\begin{array}{l}\text { Contratos de prestación de } \\
\text { servicios públicos. }\end{array}$ & Contratos de empréstito. & Contratos de suministros. \\
\hline $\begin{array}{l}\text { Contratos de prestación de } \\
\text { servicios públicos. }\end{array}$ & $\begin{array}{l}\text { Contratos con personas públicas } \\
\text { internacionales o cooperación, } \\
\text { ayuda o asistencia. }\end{array}$ & \\
\hline Contratos de obra pública. & \\
\hline
\end{tabular}

Nota: Elaboración propia.

Respecto a los contratos mencionados, se observa que el legislador fue muy celoso clasificando y mencionando de manera expresa y clara la utilización de dichas cláusulas; sin embargo, queda un interrogante, de acuerdo con la constante evolución que tiene la actividad contractual del Estado ¿las tipologías contractuales diferentes a las mencionados podrían incluirse o pactarse en estas cláusulas?

Se establece de manera puntual una respuesta negativa, ya que este tipo de prerrogativas o facultades requieren de expresa autorización legal para su incorporación y utilización como herramienta de dirección y control del contrato estatal de acuerdo con su naturaleza jurídica. Las prerrogativas de la Administración son potestades legales de naturaleza reglada, por tanto, no son atribuciones que permitan a la Administración y al participar actuar indiscriminadamente (Rodríguez Arana, 2008).

Por lo anterior, no se podría de manera consensuada por las partes, ni impuesta por la administración someter estas cláusulas en los 
demás tipos de contratos (comodato, consultoría, leasing, etc.) que no mencione el citado artículo 14 de la Ley 80 de 1993, ya que el Estado siempre debe someterse al marco legal en materia contractual pública.

De manera unánime se ha defendido que la administración puede alterar las condiciones de un contrato Estatal sin solicitar la voluntad y libertad de decisión del contratista, en ocasiones para llegar a remediar un imprevisto surgido de alguna situación adversa que impida el cumplimiento del objeto contractual. En ese orden de ideas, existe una relativa libertad discrecional que la ley otorga al Estado; discrecionalidad que brinda la posibilidad real y material de complementar de manera armónica la prevalencia del interés general (Marín, 2007).

Respecto a lo anterior, se puede entender que la doctrina ha percibido en sus diferentes conceptos y opiniones que la utilización de las cláusulas excepcionales, más allá de si son una facultad discrecionalidad, prerrogativa o inusual elemento de un contrato, es como una señal de garantías para que el contratista satisfaga esa necesidad demandada por el ciudadano común; posición manifestada de la siguiente manera:

El contrato administrativo es un instrumento al servicio de fines esencialmente públicos que, precisamente por ser tales, son intransferibles para la Administración, siendo el contratista un colaborador de ésta. Y ello conduce a una consecuencia clara: lo fundamental es que el fin público se cumpla, aun cuando ello pueda implicar la modificación del contrato celebrado. Por ello puede afirmarse que la potestas variandi encuentra su razón de ser en la inmutabilidad del fin perseguido en el contrato. (De Sola Rafecas, 1990, p. 42).

En consecuencia, se puede afirmar que existe consenso dentro de la doctrina en relación con la legitimidad frente a su utilización 
de las cláusulas excepcionales como herramienta contractual, independientemente de si esta lleva implícita un sacrificio del contratista como colaborador de la administración en probidad de cumplir fines públicos.

\section{Conclusión}

Como consecuencia de las anteriores aseveraciones, se puede concluir de manera afirmativa el acogimiento de nuestra hipótesis, en relación a la pregunta de investigación: ¿̇a utilización de las cláusulas excepcionales son o no la herramienta adecuada para asegurar el cumplimiento del objeto contractual en el contrato de obra pública en Colombia?, ya que la utilización de las cláusulas excepcionales sí es la herramienta adecuada para asegurar el cumplimiento en el contrato de obra pública en Colombia, por las continuas situaciones especiales y particulares que se presenta en sus etapas contractuales y poscontractuales, por lo que se acepta la hipótesis planteada inicialmente en este documento. Por lo tanto, los planes de estudio, investigación y delimitación de la naturaleza jurídica del contrato de obra pública, en relación con la legítima utilización de las cláusulas excepcionales, responden de manera favorable respecto al desarrollo y cumplimiento de los objetivos planteados, por lo que los dichos objetivos se cumplen así: la figura del contrato de obra pública en Colombia es por regla general uno de los instrumentos más comunes para que el Estado intente materializar sus políticas públicas, con la finalidad de proveer a los ciudadanos de bienes y servicios. Esto se plasma de manera directa en el desarrollo y ejecución del contrato de obra pública, por lo que se hace de este instrumento una manera muy práctica para cumplir los fines del Estado.

Ahora bien, el desarrollo del contrato de obra pública no siempre se cumple a cabalidad de acuerdo con lo consensuado y pactado por las partes, sea por una circunstancia previsible o no; por lo que en dicho contrato se ve envuelta la instrumentalización de las lla- 
madas cláusulas excepcionales por parte del Estado para lograr su cumplimiento. Por lo tanto, la utilización de las cláusulas excepcionales sí son la herramienta adecuada para asegurar el cumplimiento del objeto contractual, en el contrato de obra pública en Colombia.

Si bien el contrato de obra pública lleva implícita una relación contractual inicial, respecto al acuerdo de voluntades consensuadas entre las partes, este no es limitante para que una de las partes (Estado) no imponga su voluntad por encima del otro de manera legal, con la finalidad única de servir objetivamente al interés general.

El contrato de obra pública siempre debe estar conformado y representado en un extremo contractual por una entidad pública que tenga su creación de manera clara y no permita duda ni ambigüedad respecto a su naturaleza jurídica, para poder así, de manera clara y objetiva, hacer uso de las cláusulas excepcionales.

Por ser el contrato de obra pública representativo para el Estado en cuando a sus políticas públicas, este lleva inherentes una serie de situaciones y regulaciones especiales, como lo son en este caso las cláusulas excepcionales, que impactan directamente al contratista como particular colaborador de la administración.

Ahora bien, estas situaciones especiales en los contratos de obras, llamadas cláusulas excepcionales, tienen su fundamento legal directamente en la ley, ya que han sido mencionada, tratada y regulada de manera taxativa, detallada y clara en el artículo 14 de la Ley 80 de 1993, sin que permita interpretación subjetiva y caprichosa respeto a su aplicabilidad o no por parte de los operadores jurídicos contractuales.

Analizando el marco normativo del contrato de obra y las cláusulas excepcionales de la Ley 80 de 1993, se infiere de manera clara y precisa que la incorporación, aplicación y utilización de las cláu- 
sulas excepcionales en el contrato de obra pública no es opcional ni facultativos de las partes, si no por el contrario esta debe darse de manera obligatoria, por su naturaleza jurídica en aras de garantizar el objeto contractual.

La cláusula excepcional, dentro de los contratos de la obra pública por mandato legal, no pretende más que evitar la paralización o afectación grave de los servicios públicos a cargo del Estado y asegurar la inmediata, continua y adecuada prestación de dichos servicios, ya que estos son vistos como una prioridad esencial respecto a los fines del Estado, siendo a la vez una herramienta mesurada y ponderada respecto a sus fines.

La utilización de las cláusulas excepcionales dentro de los contratos de obra pública genera un rompimiento de las cargas contractuales aceptadas inicialmente, quebrantando el pacta sunt servanda del contrato.

Las cláusulas excepcionales son consideradas como una serie de prerrogativas o facultades propias del poder públicos de la administración para llevar la dirección y vigilancia de las relaciones y negociones con particulares que realizan actividades constructivas para el Estado.

El desarrollo del contrato de obra como la utilización de las cláusulas excepcionales en medio de este, llevan de manera definitiva la carga de cumplir y satisfacer la imperiosa necesidad de plasmar el cumplimiento del interés general.

Se debe trabajar de manera articulada y mancomunada entre los colaboradores de la administración (contratistas) y el Estado para poder diseñar, planear y consensuar de manera colaborativa el desarrollo del contrato de obra pública, para que este no se vea inmiscuido en la utilización de las cláusulas excepcionales, ya que 
estas, si bien son herramientas legitimas del Estado para asegurar el cumplimiento del objeto contractual, son un desgaste operativo, administrativo y legal para la administración pública.

\section{Referencias}

Alejandro Pérez, H. (2011). Exorbitancia de las prerrogativas de la administración de los contratos. Asociación Internacional del Derecho Administrativo. Biblioteca Jurídica Virtual del Instituto de Investigaciones jurídicas de la UNAM. https://revistas-colaboracion.juridicas.unam.mx/index.php/opera-prima-derecho-admin/article/view/1463.

Blanquer Criado, D. (2010). Los principios Generales del Derecho Administrativos. La Ley. Bodenheimer, E. (1997). Teoría del Derecho. Fondo de Cultura Económica.

Camacho Orozco, P. R. (2008). Curso elemental de derecho comercial general (1 ed.). Universidad Popular Del Cesar.

Cassese, S. (1994). Bases del derecho administrativo. Instituto de Administración Pública.

Dávila, L. G. (2016). Régimen jurídico de la contratación estatal (3 ed.). Universidad Externado de Colombia.

De Solas Rafecas, J. M. (1990). Contratos administrativos y contratos privados de la administración. Editorial Tecnos.

Escobar Gil, R. (1999). Teoría general de los contratos de la administración pública. Editorial Legis.

Escola, H. (1979). Tratado integral de los contratos administrativos (Volumen I). Ediciones Depalma.

Expósito Vélez, J. C. (2004). La configuración del contrato de la administración pública en el derecho colombiano y español. Universidad Externado de Colombia.

Fandiño, J. E. (2014). La contratación estatal. Editorial Leyer.

García de Enterría, E. y Fernández, T. (2006). Curso de derecho administrativo (Tomo I y II, versión latinoamericana). Edición Civitas.

García, E. R. (2017). Las facultades unilaterales en la contratación moderna (2 ed.). Editorial Legis. 
Güecha Medina, C. N. (2015) Contratos administrativos control de legalidad en el procedimiento administrativo de contratación (3 ed.). Grupo Editorial Ibáñez.

Ibagón, M. L. (2015). El principio del derecho y los contratos estatales. Universidad Externado de Colombia.

Jiménez Díaz, B. V. (2017). Aplicabilidad de las facultades excepcionales en la actividad contractual de Ecopetrol S. A. [Tesis de maestría, Universidad Santo Tomás]. Repositorio Institucional http://hdl.handle.net/11634/10546.

Ley 80 de 1993 (1993). Por la cual se expide el Estatuto General de Contratación de la Administración Pública. 28 de noviembre de 1993. D. 0. No. 41.094. http://www. secretariasenado.gov.co/senado/basedoc/ley_0080_1993.html.

Marienhoff, M. S. (1983). Tratado de derecho administrativo (Tomo III-A). Editorial Abeledo Perrot.

Marín Hernández, H. A. (2007). Discrecionalidad administrativa. Universidad Externado de Colombia.

Matallana Camacho, E. (2015). Manual de contratación de la Administración Pública: Reforma de la Ley 80 de 1993. Bogotá: Universidad Externado de Colombia.

Máximo Bezzi, 0. (1982). El contrato de obra pública. (2 ed. amp. y act.). Editorial Abeledo Perrot.

Montaña, A. (2010). Fundamentos de derecho administrativo. Universidad Externado de Colombia.

Osorio Moreno, N. D. (2013). Las cláusulas excepcionales en la actividad contractual de la administración pública ¿autonomía de la voluntad o imposición del legislador? Revista Digital de Derecho Administrativo, 3(10), 95-108. https://dialnet.unirioja.es/ servlet/articulo?codigo $=5137253$.

Palacio Jaramillo, M. T. (2011). Potestades excepcionales, nuevas prerrogativas de la administración pública y sus efectos en los procesos arbitrales. En, Araujo Oñate, R. (2011). La ley 1150 de 2007 una respuesta a la eficacia y transparencia en la contratación estatal. Editorial Universidad del Rosario.

Parada, R. (1992). Derecho Administrativo (4 ed.). Marcial Pons, Ediciones Jurídicas S.A.

Parra, W. (1999). Los Contratos Estatales (4 ed.). Librería del Profesional.

Pino, J. (2005). El régimen jurídico de los contratos estatales. Universidad Externado de Colombia. 
Rodríguez Arana, J. (2008). Las prerrogativas de la administración en los contratos de las administraciones públicas. Anuario da Facultades de Dereito da Universidade da Coruña, (12), 795-812. https://dialnet.unirioja.es/servlet/articulo?codigo=2858162.

Rodríguez Tamayo, M. (2015). Los contratos estatales en Colombia (2 ed.) Librería Jurídica Sánchez R. Ltda.

Rodríguez, G. H. (1994). Nuevos contratos estatales: comentarios a la ley 80 de 1993, con doctrinas y jurisprudencias. Librería Jurídicas Wilches.

Vargas, E. (2010). Las obras públicas. Una visión pragmática del proceso general de contratación. Ibañez. 
